\title{
A vespa do Parnaso, de Faustino Xavier de Novais, e seu intertexto imediato: as Folhas caídas, apanhadas na lama, de Camilo Castelo Branco
}

Eliana Januzzi

Universidade Federal de Minas Gerais

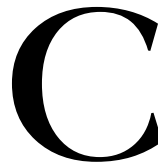

amilo Castelo Branco é nome que, no Brasil, dispensa apresentação. $\mathrm{O}$ mesmo não ocorre com o poeta também português Faustino Xavier de Novais, que, embora pouco conhecido entre nós, aqui viveu e produziu durante onze anos - de 1858 a 1869, data da sua morte. Durante esse período, escreveu poesia, prosa e teatro, bem como colaborou, de forma significativa, na imprensa carioca. Em 1862, fundou O Futuro, revista que, apesar de ter circulado por menos de um ano, possuía, segundo Jean-Michel Massa, nível superior ao das outras publicações da época. ${ }^{1}$

Primeiro livro publicado por Xavier de Novais e editado em 1854, A vespa do Parnaso foi, segundo alguns historiadores, a causa de sua saída de Portugal. Massa lembra o barulho que essa obra provocou na então pequena e provinciana Porto, e que mereceu, por isso, palavras de entusiasmo de Camilo Castelo Branco: "O teu primeiro volume era uma galeria de retratos tirados de perfil, a furto e de passagem, à maneira que os originais te acotovelavam nas praças, nos botequins e nos salóes".

${ }^{1}$ MASSA, 1971, p. 350.

${ }^{2}$ Apud MASSA, 1971, p. 345. 
A vespa do Parnaso constitui-se de dez poemas, todos compostos na linha da tradição moral, própria da sátira, gênero de escolha do poeta num momento em que esta [a sátira] desempenhava na sociedade um papel específico, como atesta Jacinto do Prado Coelho: "logo que se torna visível a feição burguesa da nova estrutura social, o desencanto e a revolta individualista formulam o primeiro protesto na poesia de Faustino Xavier de Novais contra os brasileiros e barões, a sua cupidez argentária e o seu reacionarismo."3

Estudos desenvolvidos a partir da página de rosto de $A$ vespa do Parnaso demonstram que essa apresenta um ponto de ancoragem em certo trecho do primeiro poema aí publicado. Abaixo, uma reprodução da página de rosto citada, o que facilitará a compreensão do raciocínio aqui proposto:

\section{A VESPA DO PARNASO!}

Collecç̃̃o de Poesias Lisongeiras,

POR UM MORDOMO DAS ALMAS DE CAMPANHÃ,

QUE VEM DE COLLARINHOS TEZOS METTER A

FALLAAO BUCHO AO SEU JUIZ, AUTHOR DAS

FOLFAS CAMTDAS.

Obra de $100 r^{s}$, e que vale bem um pa-

taco, por ser muito instructiva, e de

grande proveito para quem não sabe lêr.

\section{क) (9) त्रा (क)}

TIPOGRAPHIA DE J. A. DE FREITAS JUNIOR.

Rua das Flores, n. ${ }^{\text {os }} 250$ a 253. $=1854 .=$

${ }^{3}$ COElHO, 1960, p. 745. 
A referência a Folhas Caídas não aparece apenas na capa da obra, mas também no verso 56 - abaixo transcrito - do poema intitulado "A Vespa", onde esse inseto é a personificação do poeta, que ameaça punir, picando, todos aqueles que não se enquadram no seu conceito de virtude, dentre esses a dama que quer ser literata - a quem, especificamente, o poema condena por sua presunção, com a sugestão de que "Não se meta em danças altas / Entretenha-se a fiar." (v. 49-50) Ao final da estrofe, tem-se o seguinte aconselhamento, agora no plural:

\section{Tolas! nas horas perdidas, 56 Pegai nas Folhas Caidas, 57 Boa lição achareis!}

Sanches de Frias, autor de estudo biográfico-literário sobre Xavier de Novais, dá notícia de que, com a publicação de $A$ vespa do Parnaso e em conseqüência da referência a Folhas caídas contida na indicação de autoria, acreditou-se, num primeiro momento, que Novais se referia a Almeida Garrett, único autor de obra com esse nome - e que causou grande escândalo quando de sua publicação, pelo fato de, segundo a crítica da época, Garrett ter trazido a público, nos versos, os seus amores com a Viscondessa da Luz, Rosa Montufar. Eis o que registra Francisco Gomes de Amorim, biógrafo de Garrett:

Nas salas cochichava-se e lia-se avidamente os versos às escondidas. As mulheres mostravam-se indulgentes; se alguma houve que fez coro com os moralistas de réquiem, foi por não ter tido o quinhão no livro. Entre os homens, murmuravam os que eram piores que o Poeta, qualificando a publicação de 'pouca vergonha', em frase bordalenga, que afrontava a verdade e a prosódia. Coitados! ${ }^{4}$

Sanches de Frias não acredita que a referência de Novais a Folhas caidas diga respeito a Garrett. Para ele, o texto impresso na capa faz referência a Camilo Castelo Branco, que, pouco depois do aparecimento

${ }^{4}$ Apud SÁFADY, 1965, p. 19. 
de Folhas caídas, de Garrett, e meses antes da publicação de $A$ vespa do Parnaso, fizera publicar um livro de versos intitulado Folhas caidas, apanhadas na lama, também sob pseudônimo:

FOLHAS CAHIDAS, APANHADAS NA LAMA, POR UMANTIGOJUIZDASALMASDECAMPANHAN, E SÓCIOACTUALDAASSEMBLEAPORTUENSE,
COMEXERCICIONOPalheiro. OBRADEQUATRO VINTENS, EDEMUITAINSTRUCÇÃO,

\author{
PORTO: \\ TYPOGRAPHIADEF.GDAFONSECA, \\ Ruadas Hortasn. ${ }^{\circ} 152$ e 153.
}

1854

Além da especulação de que a referência feita por Novais a Folhas caidas dissesse respeito à obra de Garrett, também foi dito e escrito, na época, que $A$ vespa do Parnaso poderia ser uma resposta a Camilo Castelo Branco, do que Sanches de Frias discorda:

É inexato. Camilo, nos seus maus versos, dirigiu diatribes a diversas entidades, na generalidade. Novais, nas suas poesias, bem mais corretas e humorísticas, satirizou personagens e costumes, que em 
nada se prendem aos assuntos de Camilo, a quem somente aludiu no frontispício do seu escrito, como se acaba de ver, chamando-se, modestamente, mordomo do juiz de Campanhã. ${ }^{5}$

Uma nova possibilidade de entendimento da menção feita por Novais a Folhas caídas pode ser pensada a partir da vinculação entre a página de rosto e o verso 56 do poema "A Vespa": "Pegai nas Folhas Caidas".

Voltando à suposição inicial de que Novais se referia a Folhas caidas de Garrett, não nos parece convincente que um poeta satírico comprometido com a denúncia social desse destaque na capa do seu livro a uma obra que, como registra Sáfady, contém uma "poesia lírica no sentido mais próprio da expressão, pois todas as objetividades esbatem-se em função do sujeito, numa tentativa de 'redescoberta' do mundo dentro de si." 6

Também nos parece simplista a idéia de que Novais tenha se autointitulado "mordomo" apenas por modéstia, como sugere Sanches de Frias. Analisando a significação e os usos desse vocábulo, percebe-se que essa nem seria uma atitude tão modesta assim. Mordomo, do latim vulgar majordomu, é dicionarizado, hoje, como "administrador dos bens de uma casa, de uma irmandade, de uma confraria”. Jucá Filho registra mordomomor como "fidalgo encarregado da mordomia principal". E Dina Rodrigues Macias, em estudo recente sobre o dialeto rionorês, falado em Rio de Onor, uma freguesia portuguesa do Concelho de Bragança, dá notícia de que o mordomo exerce, ainda hoje, função da maior importância na organização daquela sociedade. Trata-se de uma comunidade híbrida, já que formada por uma aldeia dividida em dois pequenos núcleos populacionais: um espanhol e um português, distantes um do outro 150 metros. Embora separados por fronteira política, possuem a mesma cultura, o mesmo

${ }^{5}$ FRIAS. In: NOVAIS, 1906, p. 182. Frias dá notícia de que quem, na verdade, parodiou a obra de Garrett foi Pedro Dinis, que, sob o pseudônimo de Amaro Mendes Gaveta, antigo colaborador do Palito Métrico, fez publicar Folhas caidas apanhadas a dente, no mesmo ano de 1854.

${ }^{6}$ SÁFADY, 1965, p.100. 
dialeto, os mesmos costumes e a mesma economia. Assim, torna-se obrigatória a livre circulação entre esses povos, cuja sociedade é constituída por famílias, chamadas "vizinhos" e que são governadas por um Conselho formado por dois mordomos, num sistema de votação cíclica. Macias dá uma idéia do papel que representam os mordomos nessa organização

Todas as atividades do conselho e dos mordomos, embora sujeitas à tradição, adaptam-se às novas circunstâncias, mas sempre dentro dos princípios estabelecidos pelo costume. [...] Aqueles mordomos são também os responsáveis por todas as despesas públicas correntes, pela cobrança de multas e pela gestão dos bens da comunidade. Quando da preparação da eleição dos novos mordomos, normalmente no dia do Ano Novo, os mordomos cessantes, além de chamarem a atenção dos vizinhos para a necessidade de escolherem bem os novos mordomos, por se tratar de um cargo muito importante, pois vão eleger/escolher aqueles que irão dirigir os interesses da povoação, apresentam ainda as contas relativas ao ano em que eles conduziram aquele povo. ${ }^{7}$

Assim, intitular-se "mordomo das almas de Campanhã" não nos parece pouca coisa. Campanhã é uma freguesia portuguesa do Concelho do Porto, tendo sido vila e sede desse Concelho até 1836 . Vale registrar que o seu patrimônio é constituído, dentre outros, pelo Palácio do Freixo, pelo ex-edifício da Secretaria de Estado da Cultura e pela Igreja de Campanhã.

Por tudo isso, é de se acreditar que Novais, mais do que apenas "aludir" ao amigo, dispôs-se, a partir da capa do livro, a perfilar com ele na prática da sátira, ou seja, a filiar-se estética e ideologicamente a Camilo Castelo Branco.

Um dos caminhos que nos levam a essa conclusão tem como ponto de partida a menção a "Palheiro", feita por Camilo, na capa de Folhas caídas, apanhadas na lama: "sócio atual da Assembléia Portuense com exercício no Palheiro".

7 MACIAS, 2003, p. 14-15. 
Três são as notícias a que tivemos acesso do que pode significar "Palheiro". A primeira vem do próprio Camilo, em texto satírico que imita o gênero dramático, publicado no mesmo ano de 1854, logo depois da publicação de Folhas caídas, apanhadas na lama. Essa "peça" tem por assunto uma sessão realizada no "salão da Assembléia Portuense, denominado Palheiro", em que comendadores ali presentes, caricaturados como caipiras, fazem críticas e pedem providências contra a publicação de "um folheto, alumiado as Folhas caidas apanhadas na lama, no qual semos postos a redículo, com as mais trôpegas ilusōes" - aqui, uma nota esclarecedora: "Em vulgar: torpes alusões. (Nota do taquígrafo)"

Alguns anos mais tarde, em 1866, foi publicada, em Bom-senso e bom-gosto - obra que apresenta os debates em torno da "Questão Coimbrã" - o poema "Questão de Palheiro", de Urbano Loureiro, que retrata, de forma satírica, os intervenientes na polêmica."

Por fim, Eça de Queirós, em 1884, em carta dirigida a Oliveira Martins, comenta:

Filho de Aveiro, educado na Costa Nova, quase peixe de ria, eu não preciso que mandem ao meu encontro caleches e barcaças. Eu sei ir por meu próprio pé ao velho e conhecido palheiro do José Estevão [...] Talvez sexta-feira fique na Granja, a respirar o ar puro da verdade social que ali constantemente circula, emanado dos espíritos de Mariano, Henrique Macedo, e outros reforminhas. ${ }^{10}$

Recolhidas essas informações, o termo parece remeter mais a um sentido abstrato de ajuntamento de intelectuais, a uma espécie de academia de idéias, do que ao próprio local físico onde eles se ajuntam.

Certo é que a crítica à fidalguia nascida à margem da tradição, assunto que viria a ser recorrente em Novais, fica evidente no texto "O Palheiro", de Camilo Castelo Branco. Reforça, ainda, a inferência da filiação de Novais

${ }^{8}$ CASTELO BRANCO, 1990, p. 571-580.

${ }^{9}$ Cf. FERREIRA; MARINHO, 1866, p. 338-349.

${ }^{10}$ QUEIRÓS, 1983, p. 63-64. 
ao conjunto de idéias e valores do amigo a recomendação contida no verso 56, já mencionado: "Pegai nas Folhas caídas", que o contexto permite depreender tratar-se da obra de Camilo. Tal como na capa, aqui também, Novais suprime a indicação "apanhadas na lama". Entretanto, é nessa obra - e não na de Garrett - que pode ser encontrado o espírito de discriminação, já percebido em "A Vespa".

Eis a transcrição das estrofes que justificam a aproximação dos textos de Camilo Castelo Branco e de Faustino Xavier de Novais:

\section{"Elogio Fúnebre"}

"A Vespa"

a uma dama, prodígio de fecundidade, que dá à luz três romances, por semana, nos jornais do Porto

Cornucópia da toleima, Nós fizemos-te algum mal?

Tu não sabes, escritora?

Como zombam lá por fora

Das letras de Portugal?

Não lucrara mais a pátria,

E lucraras tu também,

Se fiasses numa roca,

Com primor, a maçaroca,

Que desprezas, com desdém? ${ }^{11}$
Pois quando encontro uma dama

Que literata quer ser,

E por fim bespa me chama, Sem disso a causa saber?!...

Não só então a não poupo,

Mas sinto não ter um choupo,

Do meu ferrão em lugar;

Se quer desculpa das faltas,

Não se meta em danças altas,

Entretenha-se a fiar ${ }^{12}$

Contrariando afirmação de Sanches de Frias ${ }^{13}$ de que os assuntos de Novais não se prendem aos assuntos de Camilo, a confrontação entre essas décimas demonstra que os dois textos são, sim, variantes de uma mesma estrutura.

Michael Riffaterre ensina que cada texto apresenta, no seu conjunto, uma única unidade significante, unicidade essa que resulta do fato de que

\footnotetext{
${ }^{11}$ CASTELO BRANCO, 1989, p. 741.

12 NOVAIS, 1854, p. 5.

${ }^{13}$ Cf. nota 6 deste artigo.
} 
o texto, na sua inteireza, deriva, por expansão, de uma única frase matricial. Levando-se em conta que o processo de expansão é determinado por uma série de modelos latentes, que são os textos pré-existentes, pode-se concluir que a textualidade tem por fundamento a intertextualidade.

Para que haja intertextualidade, segundo o modelo proposto por Riffaterre, é necessário que os textos que se comprometem atualizem uma invariante, e que essa atualização se imponha ao leitor graças às constantes formais e semânticas, que se manifestam a despeito de variações estilísticas entre eles. Neste estudo, as constantes que nos fizeram aproximar os textos de Camilo Castelo Branco e de Faustino Xavier de Novais estão sintetizadas na seguinte "frase matricial": "a mulher, desqualificada que é para o trabalho intelectual, deve contentar-se em operar a roca de fiar." - frase essa que dá a perceber a identidade estrutural existente entre os poemas. ${ }^{14}$

Por fim, a forma extensa usada na capa do livro de Novais, que indica não apenas a autoria: "Por um mordomo das almas de Campanhã", mas, ainda, diz a que vem: "meter a fala ao bucho ao seu Juiz, autor de Folhas caídas", dá força ao entendimento aqui proposto. Essa forma prolixa não se repetiu nos livros que Novais viria a publicar mais tarde, talvez por não se fazer mais necessário reafirmar a posição aí tomada. Tanto parece ser assim que, em edição posterior do poema "A Vespa", Novais sentiu-se à vontade para alterar os versos 55 e 56, já citados. Ao invés de recomendar Camilo Castelo Branco - posição importante e decisiva no seu primeiro livro de versos - passou a recomendar o grande satírico português Nicolau Tolentino, a quem, diga-se de paassagem, Novais era comparado. Assim, "Tolas! nas horas perdidas, / Pegai nas Folhas caidas", transformou-se em: "Se inda tendes algum tino, / Ide ler o Tolentino."15

Certo é que o poeta parece ter se mantido fiel ao compromisso assumido em $A$ vespa do Parnaso - afinal, com exceção de alguns poemas

${ }^{14}$ RIFFATERRE, 1979, p. 128-132.

${ }^{15}$ Novais apresentou o poema com essas modificações em Poesias, editada em 1856 e Novas poesias, editada em 1858, alteração que se manteve na edição póstuma de 1881 . 
da juventude, recolhidos em Poesias e Novas poesias, de 1856 e 1858, respectivamente, não se tem notícia de obra sua, publicada em vida, que não seja satírica, e que não tenha por base a crítica ao sistema de valores de uma sociedade, que engrandecia o sujeito não por suas virtudes, mas pelo título que ostentava.

\section{Referências}

CASTELO BRANCO, Camilo. Obras completas. Justino Mendes de Almeida (Org.). Porto: Lello \& Irmão, v. X, 1989.

CASTELO BRANCO, Camilo. Palheiro. In: . Obras completas. Justino Mendes de Almeida (Org.). Porto: Lello \& Irmão, v. XII, 1990, p. 571-578.

COELHO, Jacinto do Prado. (Dir.) Dicionário de literaturas brasileira e galega. Porto: Figueirinhas, 1960, p. 244-248; 737-747.

FERREIRA, Alberto; MARINHO, Maria José. Bom senso e bom gosto (A questão coimbrã). 2. ed. Portugal: Maiadouro, 1866 (impresso para a Imprensa Nacional / Casa da Moeda)

JUCÁ FILHO, Cândido. Dicionário escolar das dificuldades da lingua portuguesa. 4. ed. Rio de Janeiro: FENAME/Ministério da Educação e Cultura, 1970.

MACIAS, Dina Rodrigues. Dialeto rionorês: contributo para o seu estudo. Bragança/Portugal: Instituto Politécnico de Bragança, 2003.

MASSA, Jean-Michel. A juventude de Machado de Assis. Trad. Marco Aurélio de Moura Matos. Rio de Janeiro: Civilização Brasileira, 1971.

NOVAIS, Faustino Xavier de. A vespa do Parnaso. Porto: J. A. de Freitas Júnior, 1854.

NOVAIS, Faustino Xavier de. Poesias. 2. ed. Porto: Tipografia de Sebastião José Pereira, 1856.

NOVAIS, Faustino Xavier de. Novas poesias. 2. ed. Porto: [s.e.], 1858. 307p. [Prefácio de Camilo Castelo Branco]. 
NOVAIS, Faustino Xavier de. Novas poesias de Faustino Xavier de Novais, precedidas dum juizo crítico de Camilo Castelo Branco. Lisboa, 1881.

NOVAIS, Faustino Xavier de. Ignez d'Horta: comédia semi-trágica em 5 actos. João Baptista Gomes, Sanches de Frias (Org.). Lisboa: Viuva Tavares Cardoso, 1906, 261p.

QUEIRÓS, Eça de. Correspondência. CASTILHO, Guilherme de. (Org.). Lisboa: Imprensa Nacional, 1983, v. 1.

RIFFATERRE, Michael. Sémiotique intertextuelle: l'interprétant Rhétoriques, sémiotiques. Revue d'Esthétique, n. 1-2. Paris: Union Générale d'Éditions, 1979.

SÁFADY, Naief. Folhas caidas: a crítica e a poesia. 2. ed. rev., seguida do texto integral de Almeida Garrett. Rio de Janeiro: Livraria Francisco Alves, 1965. (Coleção "Universitas").

\section{Resumo}

Estudo da página de rosto de $A$ vespa do Parnaso, obra de poesias satíricas de Faustino Xavier de Novais, que apresenta um ponto de ancoragem em certo trecho do primeiro poema aí publicado, "A Vespa". Esse ponto de ancoragem remete a uma vinculação com um texto de Camilo Castelo Branco, no qual se percebe uma tomada de posição, quanto ao gênero satírico, que Xavier de Novais adotaria dali por diante.

\section{Résumé}

Étude de la page de titre de l'A vespa do Parnaso, oeuvre de poésies satiriques de Faustino Xavier de Novais, qui présente un point d'ancrage dans certain passage du premier poème y publié, "A Vespa". Ce point d'ancrage fait une liaison avec un texte de Camilo Castelo Branco, dans lequel on s'apperçoit une prise de position en rélation au genre satirique que Xavier de Novais prendrait dorénavant. 